\title{
Insulin Resistance in Type 1 Diabetes: Evidence and New Insights
}

\author{
Paola Irma Guidone ${ }^{1}$, Paola Di Filippo ${ }^{1 *}$ and Stefano Tumini ${ }^{1,2}$ \\ ${ }^{1}$ Department of Paediatrics, University of Chieti, Italy \\ ${ }^{2}$ Center of Pediatric Diabetology, University of Chieti, Italy
}

Submission: February 12, 2018; Published: March 14, 2018

*Corresponding author: Paola Di Filippo, Department of Paediatrics, University of Chieti, Via dei Vestini, 66100, Chieti, Italy, Email: paolina_@hotmail.it

\begin{abstract}
Although the main etiopathogenic mechanism of Type 1 Diabetes Mellitus is autoimmunity, over the past decade it has been shown that Insulin Resistance also plays a key role in the pathogenesis and in the development of micro- and macrovascular complications, defininig a condition termed as "double diabetes". Double diabetes has increased with the raised trend of obesity and it could explain the increased risk of cardiovascular complications in Type 1 Diabetes Mellitus subjects compared to the general population, even in condition of good glycaemic control. There are some tools that allow to use clinical parameters to quantify Insulin Resistance but especially the beneficial effect of complications prevention measures. Recently it has been shown that the management of the metabolic syndrome components can also be effective in reducing the cardiovascular risk in patients with Type 1 Diabetes since the pediatric age.
\end{abstract}

Keywords: Type 1 Diabetes; Double diabetes; Insulin resistance; Complications; Glycaemic control

Abbreviations: T1DM: Type 1 Diabetes Mellitus; IR: Insulin Resistance; CV: Cardiovascular; MS: Metabolic Syndrome; HOMA-IR: Homeostasis Model Assessment of Insulin Resistance; QUICKI: Quantitative Insulin Sensitivity Check Index; HbA1c: Glycosylated Hemoglobin; LDL: LowDensity Lypoprotein; BMI: Body Mass Index

\section{Introduction}

Type 1 Diabetes Mellitus (T1DM) is an autoimmune disorder characterized by beta-cells destruction and absolute insulin deficiency. Pathogenesis of T1DM is different from that of type 2 diabetes mellitus, where both insulin resistance (IR) and reduced secretion of insulin by the beta-cells play a synergistic role [1]. Although the main etiopathogenic mechanism of T1DM is autoimmunity, over the past decade it has been shown that IR also plays a key role in the pathogenesis [2-4] and in the development of micro- and macrovascular complications [5,6]. In fact, recent insight from the Diabetes Control and Complications Trial (DCCT) showed that IR predisposes to micro- and macrovascular complications, suggesting the concept of "double diabetes" [7]. The term "double diabetes" was first used in 1991 to describe a combination of T1DM with clinical features of Type 2 Diabetes Mellitus (T2DM) and exacerbation of IR, that is, the inability of a known quantity of insulin (exogenous or endogenous) to increase glucose uptake [8]. IR is driven by central adiposity and subsequent cytokine-mediated systemic inflammatory response as well as elevated circulating free fatty acids, determing a condition known as metabolic syndrome (MS) and all comorbidities associated with it [5].

\section{Discussion}

It is well known that patients with T1DM are at particularly high risk of cardiovascular disease already, so there has been concern that this increase in body weight may only add to this likelihood, with intensively treated patients being placed at especial risk [7].

The prevalence of double diabetes has increased with the raised trend of obesity and it could explain the increased risk of cardiovascular complications in T1DM subjects compared to the general population, even in condition of good glycaemic control [9-12]. Normal body weight in T1DM patients is a deep-rooted concept in scientific literature, but recently it was observed an increased prevalence of overweight and obesity in these subjects just as in the general population, which has recently been esteemed equal to $22.1 \%$ [13,14].

On the other hand it was suggested that excess weight gain in children could be an "accelerating factor" [4] for development of T1DM in the Pittsburgh cohort [14] and in another study from Finland [15]. The mechanisms involved in the development of IR in normal- or low-weight T1DM patients are different: portal and 


\section{Current Research in Diabetes \& Obesity Journal}

systemic hypoinsulinization with alteration of the axes related to growth hormone, glucagon, and leptin cause metabolic and hormonal changes perpetuating glucotoxicity and leading to increased IR [16]. Poor glycaemic control in type 1 diabetics is associated with hepatic IR, while whole-body glucose utilization was reported to be lower even in those who were well controlled $[17,18]$.

Moreover, insulin sensitivity decreases physiologically during the later pubertal stages, in order to increase the substrates availability. In fact, during puberty a selective IR, that is restricted to peripheral glucose metabolism, leads to compensatory hyperinsulinemia and it amplificates protein anabolism, fat utilization as alternative fuel and lean muscle preservation during growth $[19,20]$. Therefore, in adolescent patients with T1DM insulin dose requirements increase by up to $30 \%$. IR may also be related to sedentary lifestyle, family history of type 2 diabetes and weight gain associated with intensive insulin therapy [21].

Several studies have shown that IR may predict the risk of microalbuminuria, retinopathy, and neuropathy [22]. Although the role of IR in the development of complications in T1DM1 is known, how to quantify it objectively remains unclear. The gold standard test for measuring insulin sensitivity is representd by euglycaemic-hyperinsulinemic clamp, but it is invasive, expensive and mainly used in research settings [23], whereas HOMA-IR (Homeostasis Model Assessment of Insulin Resistance) or QUICKI (Quantitative Insulin Sensitivity Check Index) cannot be used in patients on insulin treatment [24] and the calculation of daily insulin requirements is not accurate depending on multiple factors $[24,25]$. This difficulty led to the creation of two validated clinical scores, developed using mathematical models: the Insulin-Sensitivity Score (ISS) for children and adolescents with diabetes, validated with the clamp [26] and the estimated Glucose Disposal Rate (eGDR) [24], with a high correlation with the clamp. The weakness of the first score is that the study population consisted of both children with T1DM and children with T2DM. The second one is a model whose values are inversely correlated to the degree of IR, with adult patients diagnosed with MS having lower eGDR values than those with no MS criteria [5,24,27-29]. Values of eGDR values were lower also in obese children with T1DM older than 11 years: this may therefore be considered a marker of IR also in children. Insulin dose was higher in diabetic patients with overweight or obesity, especially in IU/m2/day [25].

Kilpatrick et al. [5] found similar results: the eGDR at baseline strongly predicted the development of retinopathy, nephropathy, and cardiovascular disease (both micro- and macrovascular complications) whereas insulin dose and International Diabetes Federation (IDF)-defined MS were poor predictors [5].These findings are consistent with those from the Pittsburgh Epidemiology of Diabetes Complications Study: low
eGDR (and therefore high IR) seems to be associated with an increased risk of nephropathy [30], peripheral vascular disease [31], and coronary artery disease [32].

A recent study involving 17,050 individuals from Swedish National Diabetes Register, found that there is a strong association between eGDR and all-cause mortality, as well as cardiovascular mortality, in individuals with T1DM. All these findings may guide preventive measures by improving risk assessment in individuals with T1DM [33]. There has been a growing interest in exploring the role of adjunctive therapy in T1DM with the aim of improving insulin sensitivity and glycemic control, limiting the insulin dose and weight gain and the long-term possibility of $\mathrm{CV}$ risk reduction. On this topic, a meta-analysis by Liu et al. [34] included eight trials of metformin versus placebo: the use of metformin was associated with a reduction in weight, total daily insulin dose and total and Low-Density Lypoprotein (LDL) cholesterol, without an increased risk of hypoglycemia or ketoacidosis [34,35].

At the same time, the REMOVAL Study, the largest multicenter, double-blind, placebo-controlled trial, has assessed similar results in terms of reduction in body weight and LDL cholesterol without an increased risk of hypoglycemia or ketoacidosis [36]. Interestingly, none of the studies demonstrated a sustained reduction in $\mathrm{HbA1c}$ as if to confirm that glycemic control is often independent of mechanisms of IR. Little is studied about effective interventions for weight management in this population [37]. Dietary intervention, increased physical exercise, adjustment of insulin doses, adding other diabetes medications that positively impact body weight could improve insulin sensitivity [37].

As a target of vascular complications, other metabolically active and richly vascularized districts have also been studied. Recently components of MS and IR have been associated with lower trabecular bone quality in adults with T1DM when compared to age-, sex- and body mass index (BMI) -matched adults without diabetes and this finding seems to motivate the increase of fractures in young adults with T1DM [38]. This negative effects of T1DM on bone geometry, quality, and bone markers probably start in childhood, as demonstrated by Franceschi et al. [39]. In addition to the vascular alteration which could explain these findings, some studies have found an association between Vitamin D insufficiency in individuals with T1DM and risk for insulin resistance, even after adjustment for BMI [40].

\section{Conclusion}

The most important epidemiological trials have shown the importance of metabolic control for the prevention of microangiopathic complications. Recent studies have demonstrated the relevance of weight and all other MS components management in $\mathrm{CV}$ risk prevention in T1DM patients since the pediatric age. 


\section{Current Research in Diabetes \& Obesity Journal}

\section{References}

1. Paschou SA, Papadopoulou Marketou N, Chrousos GP, Kanaka Gantenbein C (2018) On type 1 diabetes mellitus pathogenesis. Endocr Connect 7(1): 38-46.

2. Wilkin TJ (2001) The accelerator hypothesis: weight gain as the missing link between type I and type II diabetes. Diabetologia 44(7): 914-922.

3. Knerr I, Wolf J, Reinehr T, Stachow R, Grabert M, et al. (2005) The "accelerator hypothesis": relationship between weight, height, body mass index and age at diagnosis in a large cohort of 9248 German and Austrian children with type 1 diabetes mellitus. Diabetologia 48(12): 2501-2504.

4. Wilkin TJ (2008) Diabetes: 1 and 2, or one and the same? Progress with the accelerator hypothesis. Pediatr Diabetes 9(3 Pt 2): 23-32.

5. Kilpatrick ES, Rigby AS, Atkin SL (2007) Insulin resistance, the metabolic syndrome and complication risk in type 1 diabetes: "double diabetes" in the diabetes control and complications trial. Diabetes Care 30(3): 707-712

6. Soedamah Muthu SS, Chaturved N, Toeller M, Ferriss B, Reboldi P, et al. (2004) Risk factors for coronary heart disease in type 1 diabetic patients in Europe: the EURODIAB prospective complications study. Diabetes Care 27(2): 530-537.

7. Purnell JQ Zinman B, Brunzell JD, DCCT/EDIC Research Group (2013) The effect of excess weight gain with intensive diabetes mellitus treatment on cardiovascular disease risk factors and atherosclerosis in type 1 diabetes mellitus: results from the diabetes control and complications trial/epidemiology of diabetes interventions and complications study (DCCT/EDIC) study. Circulation 127(2): 180-187.

8. Teupe B, Bergis K (1991) Epidemiological evidence for "double diabetes". Lancet 337(8737): 361-362.

9. Cleland SJ, Fisher BM, Colhoun HM, Sattar N, Petrie JR (2013) Insulin resistance in type 1 diabetes: what is 'double diabetes' and what are the risks? Diabetologia 56(7): 1462-1470.

10. Cleland SJ (2012) Cardiovascular risk in double diabetes mellituswhen two worlds collide. Nat Rev Endocrinol 8(8): 476-485.

11. Rawshani A, Rawshani A, Franzen S, Eliasson B, Svensson AM, et al. (2017) Range of risk factor levels: control, mortality, and cardiovascular outcomes in type 1 diabetes mellitus. Circulation 135(16): 1522-1531.

12. Lind M, Svensson AM, Kosiborod M, Gudbjörnsdottir S, Pivodic A, et al. (2014) Glycemic control and excess mortality in type 1 diabetes. N Engl J Med 371(21): 1972-1982.

13. Polsky S, Ellis SL (2015) Obesity, insulin resistance, and type 1 diabetes mellitus. Curr Opin Endocrinol Diabetes Obes 22(4): 277-282.

14. Libman IM, Pietropaolo M, Arslanian SA, LaPorte RE, Becker DJ (2003) Changing prevalence of overweight children and adolescents at onset of insulin-treated diabetes. Diabetes Care 26(10): 2871-2875.

15. Hypponen E, Virtanen SM, Kenward MG, Knip M, Akerblom HK (2000) Childhood diabetes in Finlad study group. Obesity, increased linear growth and risk of type 1 diabetes in children. Diabetes Care 23(12): 1755-1760

16. Amitani M, AsakawaA, Amitani H, Inui A (2013) The role of leptin in the control of insulin-glucose axis. Front Neurosci 7: 51

17. Kaul K, Apostolopoulou M, Roden M (2015) Insulin resistance in type 1 diabetes mellitus. Metabolism 64(12): 1629-1639.

18. Bacha F, Klinepeter Bartz S (2016) Insulin resistance, role of metformin and other non-insulin therapies in pediatric type 1 diabetes. Pediatr Diabetes 17(8): 545-558.
19. Amiel SA, Caprio S, Sherwin RS, Plewe G, Haymond MW, (1991) Insulin resistance of puberty: a defect restricted to peripheral glucose metabolism. J Clin Endocrinol Metab 72(2): 277-282.

20. Kelsey MM, Zeitler PS (2016) Insulin Resistance of Puberty. Curr Diab Rep 16(7): 64

21. Gagan P, Sanjay K (2018) A Review of insulin resistance in type 1 diabetes: is there a place for adjunctive metformin? Diabetes Ther 9(1): 349-361.

22. Tesfaye S, Chaturvedi N, Eaton SE, Ward JD, Manes C, et al. (2005) Vascular risk factors and diabetic neuropathy. N Engl J Med 352(4): 341-350.

23. DeFronzo RA, Tobin JD, Andres R (1979) Glucose clamp technique: a method for quantifying insulin secretion and resistance. Am J Physiol 237(3): E214-E223.

24. Williams KV, Erbey JR, Becker D, Arslanian S, Orchard TJ (2000) Can clinical factors estimate insulin resistance in type 1 diabetes? Diabetes 49(4): 626-632

25. Palomo Atance E, Ballester Herrera MJ, Giralt Muiña P, Ruiz Cano R, León Martín A, et al. (2013) Estimated glucose disposal rate in patients under 18 years of age with type 1 diabetes mellitus and overweight or obesity. Endocrinol Nutr 60(7): 379-385

26. Dabelea D, D'Agostino RB, Mason CC, West N, Hamman RF, et al. (2011) Development, validation and use of an insulin sensitivity score in youths with diabetes: the SEARCH for diabetes in youth study. Diabetologia 54(1): 78-86.

27. Chillarón JJ, Goday A, Pedro Botet J (2008) Síndrome metabólico, dia-betes mellitus tipo 1 y resistencia a la insulina. Med Clin (Barc) 130(12): 466-71.4.

28. Chillarón JJ, Goday A, Flores Le Roux JA, Benaiges D, Carrera MJ, et al (2009) Estimated glucose disposal rate in assessment of the metabolic syndrome and microvascular complications in patients with type 1 diabetes. J Clin Endocrinol Metab 94(9): 3530-3534.

29. Pambianco G, Costacou T, Orchard TJ (2007) The prediction of major outcomes of type 1 diabetes: a 12-year prospective evaluationof three separate definitions of the metabolic syndrome and their components and estimated glucose disposal rate. Diabetes Care 30(5): 1248-1254.

30. Orchard TJ, Chang YF, Ferrell RE, Petro N, Ellis DE (2002) Nephropathy in type 1 diabetes: a manifestation of insulin resistance and multiple genetic susceptibilities? Kindey Int 62(3): 963-970.

31. Olson JC, Erbey JR, Forrest KYZ, Williams K, Becker DJ, et al. (2002) Glycemia (or, in women, estimated glucose disposal rate) predict lower extremity arterial disease events in type 1 diabetes. Metabolism 51(2): 248-254.

32. Orchard TJ, Olson JC, Erbey JR, Williams K, Forrest KYZ, et al. (2003) Insulin resistance-related factors, but not glycemia, predict coronary artery disease in type 1 diabetes: 10-year follow-up data from the Pittsburgh Epidemiology of Diabetes Complications study. Diabetes Care 26(5): 1374-1379.

33. Nystrom T, Holzmann MJ, Eliasson B, Svensson AM, Sartipy U (2017) Estimated glucose disposal rate predicts mortality in adults with type 1 diabetes. Diabetes Obes Metab 20(3): 556-563.

34. Liu C, Wu D, Zheng X, Li P, Li L (2015) Efficacy and safety of metformin for patients with type 1 diabetes mellitus: a meta-analysis. Diabetes Technol Ther 17(2): 142-148.

35. Meng H, Zhang A, Liang Y, Hao J, Zhang X, et al. (2018) Effect of metformin on glycemic control in patients with Type 1 diabetes: a meta-analysis of randomized controlled trials. Diabetes Metab Res Rev. 


\section{Current Research in Diabetes \& Obesity Journal}

36. Petrie JR, Chaturvedi N, Ford I, Brouwers MCGJ, Greenlaw N, et al. (2017) Cardiovascular and metabolic effects of metformin in patients with type 1 diabetes (REMOVAL): a double-blind, randomised, placebocontrolled trial. Lancet Diabetes Endocrinol 5(8): 597-609.

37. Mottalib A, Kasetty M, Mar JY, Elseaidy T, Ashrafzadeh S, et al. (2017) Weight management in patients with Type 1 diabetes and obesity. Curr Diab Rep 17(10): 92

38. Shah VN, Sippl R, Joshee P, Pyle L, Kohrt WM, et al. (2017) Trabecular bone quality is lower in adults with type 1 diabetes and is negatively associated with insulin resistance. Osteoporos Int 29(3): 733-739.

his work is licensed under Creative

Commons Attribution 4.0 Licens

DOI: 10.19080/CRDOJ.2018.06.555686
39. Franceschi R, Longhi S, Cauvin V, Fassio A, Gallo G, et al. (2017) Bone geometry, quality, and bone markers in children with type 1 diabetes mellitus. Calcif Tissue Int.

40. The NS, Crandell JL, Lawrence JM, King IB, Dabelea D, et al. (2013) Vitamin D in youth with Type 1 diabetes: prevalence of insufficiency and association with insulin resistance in the SEARCH nutrition ancillary study. Diabet Med 30(11): 1324-1332.

Your next submission with Juniper Publishers will reach you the below assets

- Quality Editorial service

- Swift Peer Review

- Reprints availability

- E-prints Service

- Manuscript Podcast for convenient understanding

- Global attainment for your research

- Manuscript accessibility in different formats

( Pdf, E-pub, Full Text, Audio)

- Unceasing customer service

Track the below URL for one-step submission https://juniperpublishers.com/online-submission.php 